\title{
THE EFFECT OF FLOOR FINISHING MATERIALS ON SURROUNDED ENVIRONMENT IN HOT ARID REGIONS WITH REFERENCE TO "AL - NAHDA ROAD PARK, RIYADH, SAUDI ARABIA"
}

\section{Waleed Mohamed Abanomy}

Assistant professor, Dept. of Architecture and Planning, College of

Architecture and Planning, King Saud University,

P.O. Box 57448, Riyadh, 11574, Kingdom of Saudi Arabia

Fax:0096614675775 -E-mail: amwaleed@yahoo.com

(Received June 21, 2009 Accepted December 19, 2009).

This research evaluates the influence of finishing materials on surrounded air temperature and relative humidity $(R H)$. The main aim of this research is to demonstrate design strategies and recommendations in order to improve the thermal performance of open spaces in hot arid regions in general and in Riyadh city in particular. Field experiments and observation were conducted in Al - Nahda Road Park, Riyadh, Saudi Arabia. Readings of air temperature and $R H$ were taken over different type of finishing materials (shaded and exposed to the solar radiation) to assess the influences of the materials and shading devices on the surrounded environment in each selected location inside the Park. Results analysis shows that shaded grass has significant effect on the surrounded air temperature reduction. The results also, emphasize that concrete and asphalt as finishing materials should be avoided in sitting and/or pedestrian areas. The results also demonstrate the importance of isolating open spaces from heat sources such as traffic vehicles.

Keywords: Finishing and floor Materials, Environmental Design, Public Parks, Hot Arid Regions

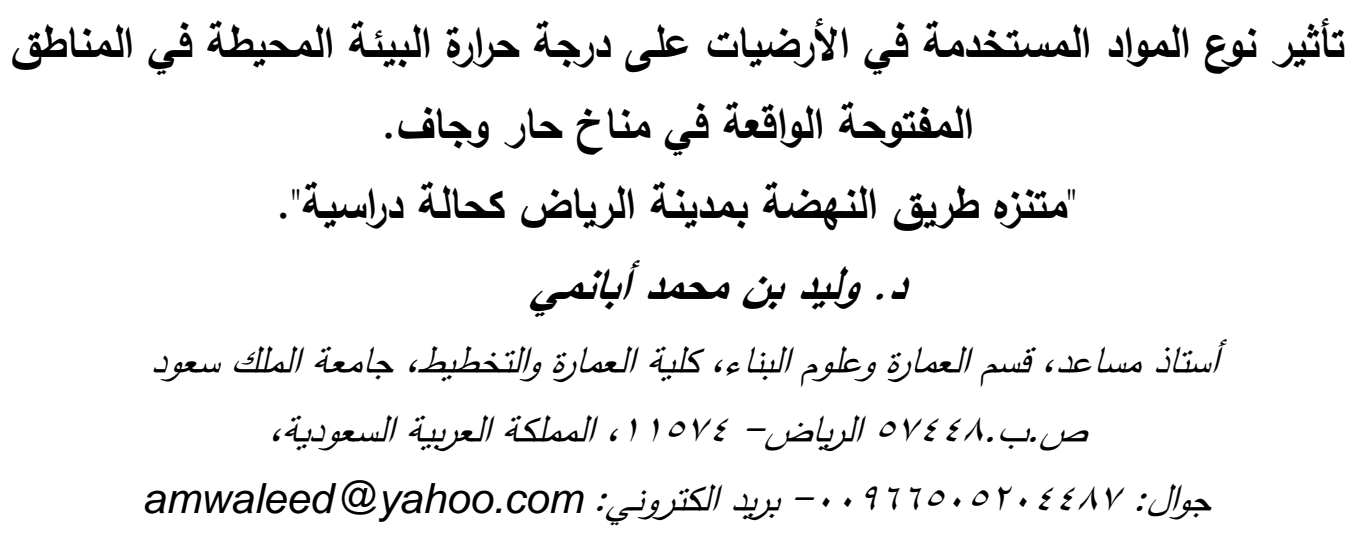

الكلمات الافتتاحية: مواد بناء، تصميم بيئي، منتزهات عامة، مناخ حار جاف. 


\section{ملخص البحث :}

يركز هذا البحث، على دراسة تأثير نوع المواد المستخدمة في الأرضيات على درجة حرارة البيئة المحيطة ومعرفة

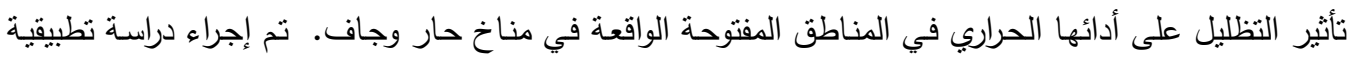

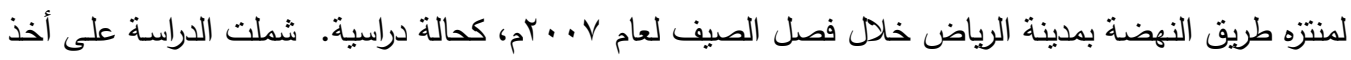

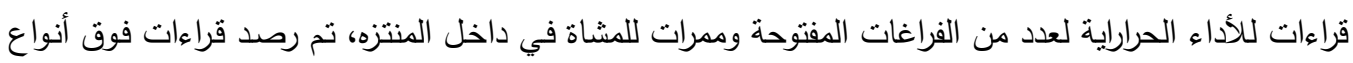

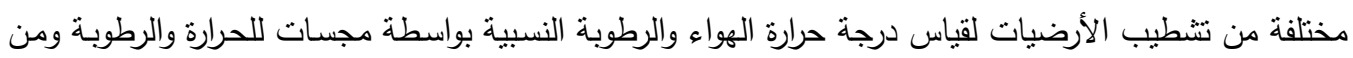

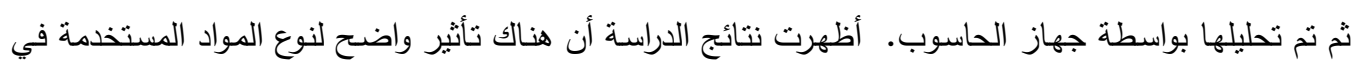

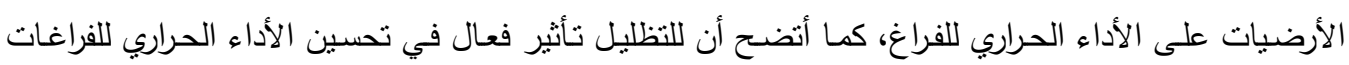

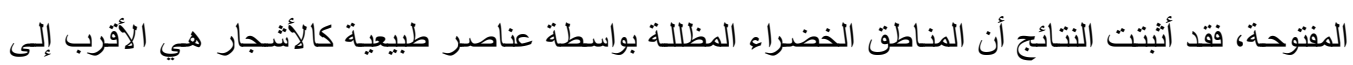

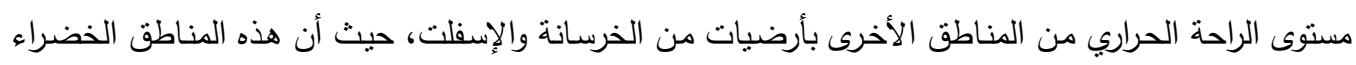

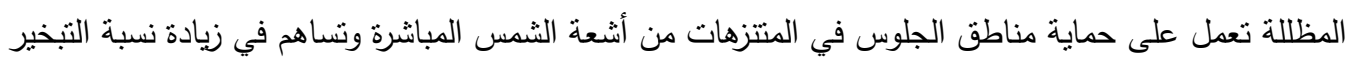

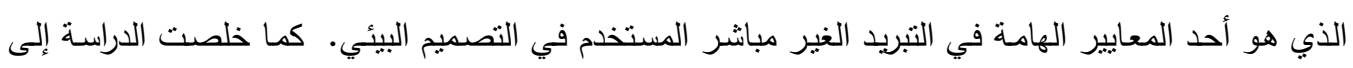

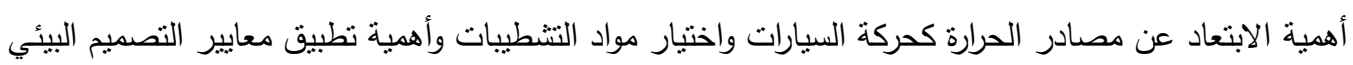

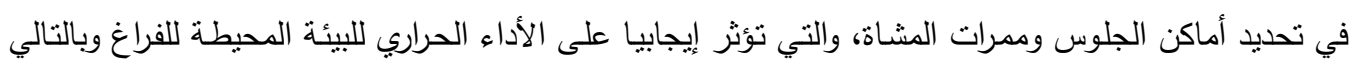
يمكن الاقتراب من نطاق الراحة الحراري لمستخدمي المكان.

\section{مقدمة :}

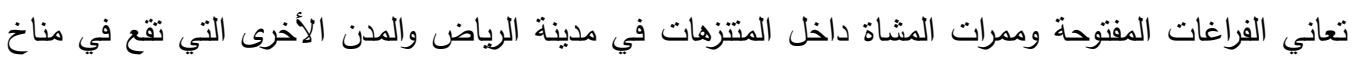

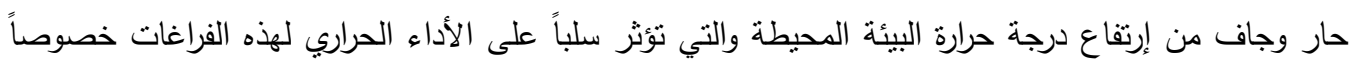

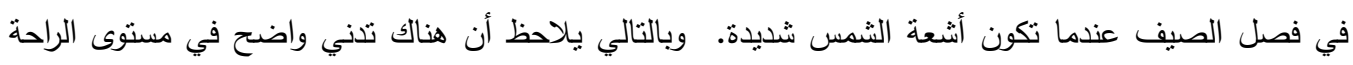

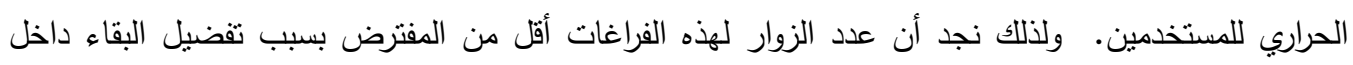

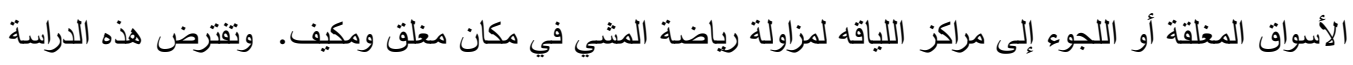

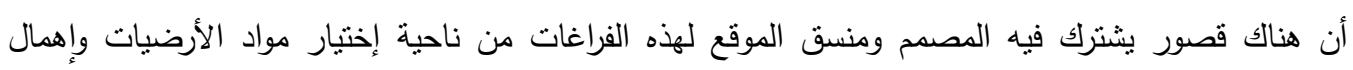

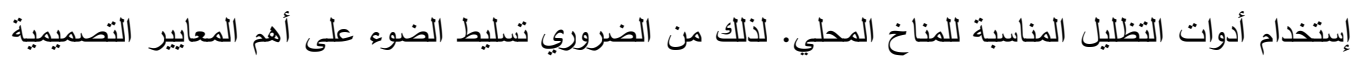

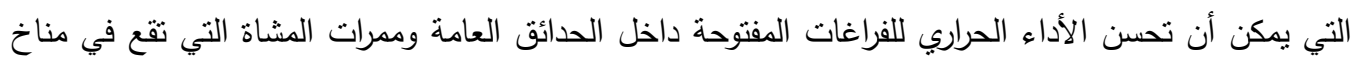
حار جاف.

يهذف هذا البحث إلى التحقق من مدى تأثير نوع المواد المستخدمة في تمهيد الأرضيات وأدوات التظليل في

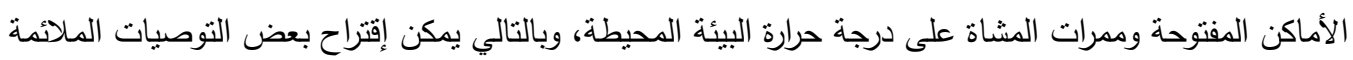

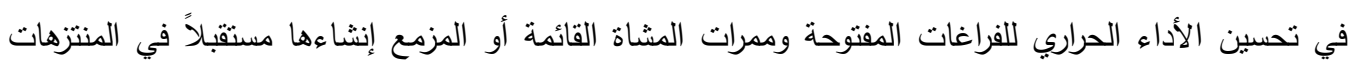
العامة في منطقة الرياض والمناطق الأخرى التي تقع في مناخ مشابه. 


\section{أدبيات البحث : n}

إن أحد أهم معايير التصميم البيئي في المناطع الحارة والجافة هو إختيار المواد المناسبة في البناء والتتييد ومنها المواد المستخدمة في تبليط وتمهيد المناطق المفتوحة وممرات المشاة داخل المتتزهات مما له الأثز الواضح في تغيير حرارة البيئة المحيطة وبالتالي يمكن أن تؤثر سالباً أو إيجابا بشكل مباشر على مستوى الراحة

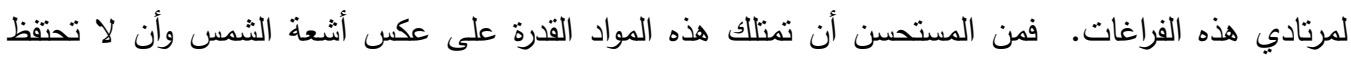
بالحرارة المكتسبة من أشعة الثمس المباشرة وغير مباشرة. ومن أهم العوامل المؤئرة على درجة الحرارة في الأماكن

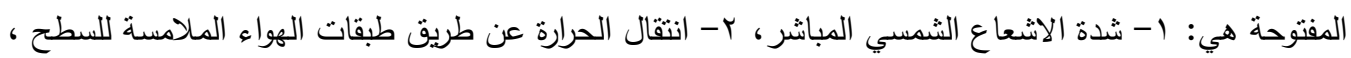
r- حركة الهواء.

مما لا شك فيه أن نوعية الأرضيات المستخدمة في الفراغات المفتوحة وممرات المشاة لها تأثير واضح

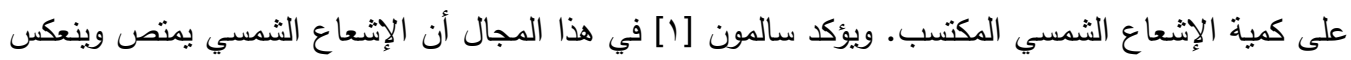
ويتخلل بواسطة العناصر والمواد المستخدمة خارجياً. فبعض المواد تسنطيع أن تعكس الأشعة الساقطة عليها بشكل أكبر من غيرها، فعلى سبيل المثال، الأسطح ذات الألوان الفاتحة تعكس الأشعة الساقطة عليها أكثر من فئنسئ الأسطح المدهونة بألوان داكنة وأيضاً الأرضيات مصقولة الأسطح تعكس أشعة الثمس أكثر من ذات الأسطح

الخثنة.

وأيضا ينصح باستخدام مواد في الأسطح ذات معامل الانبعاث قليل لكي تساعد على تقليل معدل امتصاص الحرارة، لذلك يجب أخذ الحذر في إختيار مواد التشطيب الخارجية والتي تتنائم مع المناخ الحار الجاف. فمن الضروري الإستفادة من خصائص العناصر الطبيعية في تحسين البيئة المحيطة، ويفضل إستخدام الأحجار الطبيعية التي توضع مباشرة فوق التربة أو الإنجيلة الخضراء بدون مواد لصق لكي لاتمنص ولاتحتفظ

بالحرارة.

ويمكن أيضاً النجيلة الخضراء الطبيعية أن تخفض درجة حرارة الهواء القريب من الأرض خصوصاً إذا كانت هذه الأرضيات مظللة بالأشجار [r]. كما أن الغطاء الأخضر الطبيعي يقلل من الإشعاع الثمسي

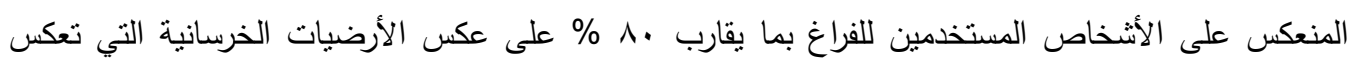
مايقارب • ــ \% من الأشعة الساقطة عليها [ب]، [ع].

وللتظليل دور أساسي في تحسين الأداء الحراري للأرضيات أباً كان نوعها. فلأشجار والغطاء الأخضر بشتى أنواعه أثز كبير في تغيير شدة أثنعة الثمس، والرياح، ودرجة حرارة البيئة المحيطة بالمبنى. وقد أكد ياناس [0] أنه يمكن للفراغ المفتوح في الموقع أن يكون له أثر واضح على أشعة الثمس والرياح ودرجة الحرارة وتبادل الإشعاع الحراري في المواد القريبة من الأرض. كما أن تتسيق الموقع والمعالجات المناخية الأخرى تساعد في تحسين أداء البيئة المحيطة بالمبنى والمناطق المفتوحة أيضاً. وقد ذكر كوك [؟] أنه من الممكن أن تحقق التربة الإنة والغطاء الأخضر (كالإنجيلة الخضراء) مع النظليل مستوى الراحة الحراري في الفراغات المفتوحة الواقعة في مناخ حار وجاف. كما أكد جولاني [V] أنه يمكن للأشجار المحيطة بالفراغ المفتوح أو ممر المشاة أن تخفض شدة 
أشعة الثمس الساقطة بشكل مباشر من الثمس والمنعكسة من المباني المحيطة وبالثالي فهي أداه فعالة لنوفير فراغ مقبول وقريب من مستوى الراحة الحراري للإنسان.

يعثبر الإثعاع الثمسي من أهم مصادر الحرارة في الفراغات المفتوحة خاصةً في الدناطق الحارة

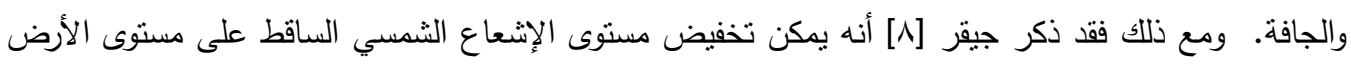

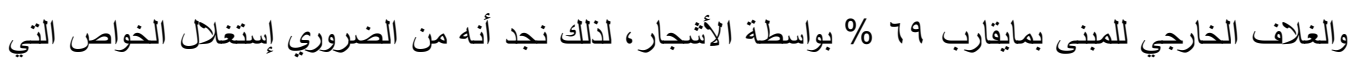

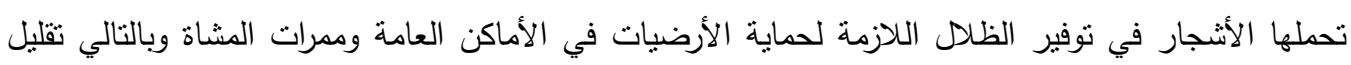

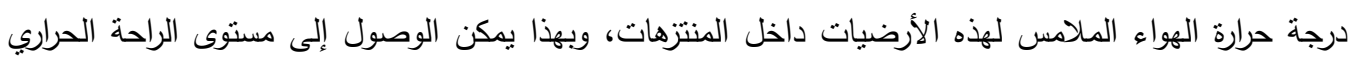
لمرتادي الفراغات الخارجية الواقعة بين المباني و المنتزهات.

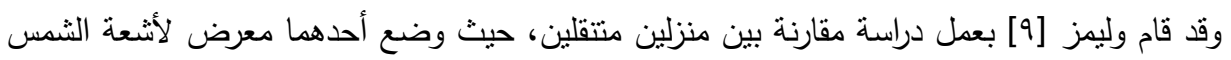

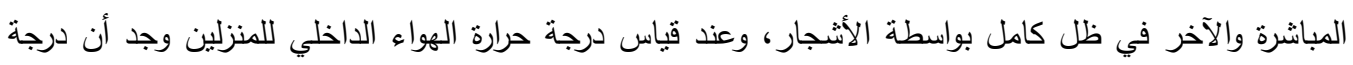

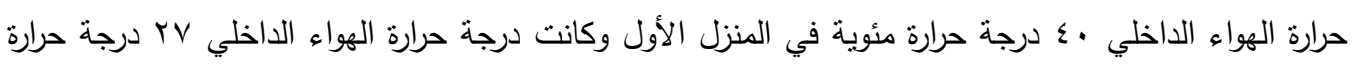

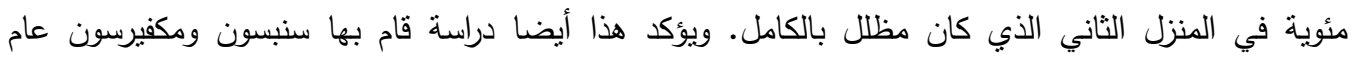

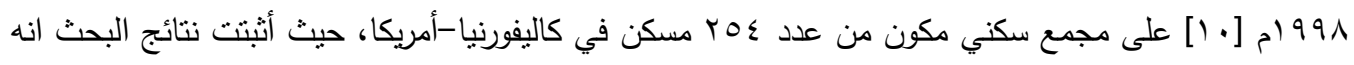

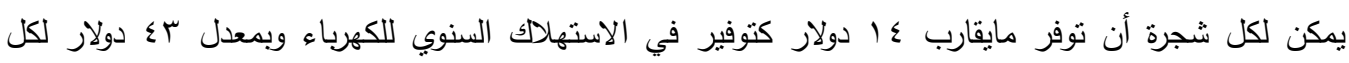

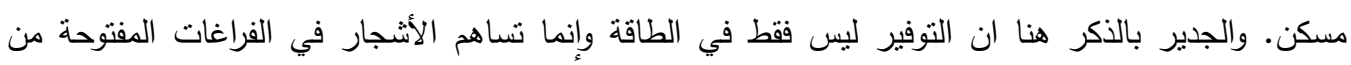

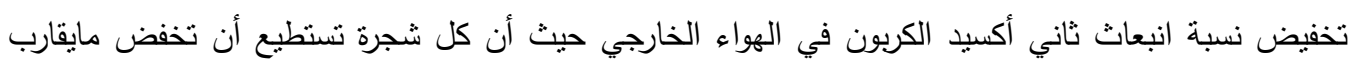

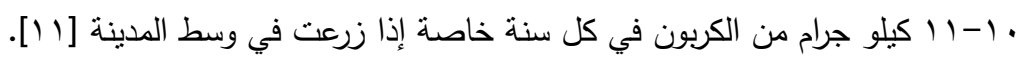

ولكن الحذر مطلوب في اختبار نوع الأشجار حيث يفضل أن لا تحجب الأشجار أشعة الشمس في

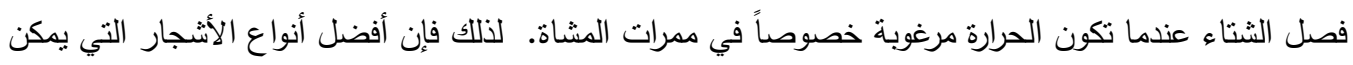

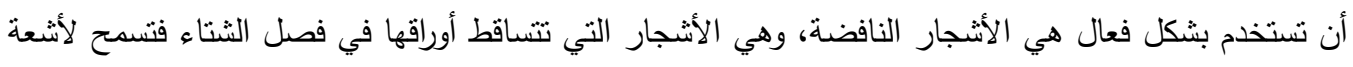

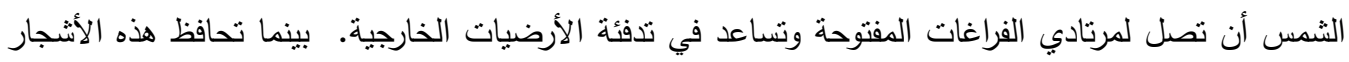
بأوراقها الكثيفة في فصل الصيف لتوفر الظل اللازم لحماية المستخدمين والأرضيات من أثنعة الثنمس الحارة.

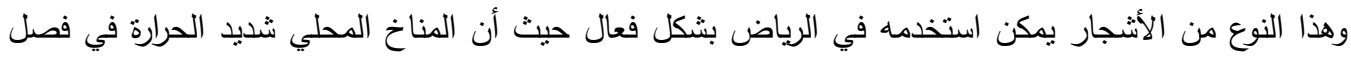

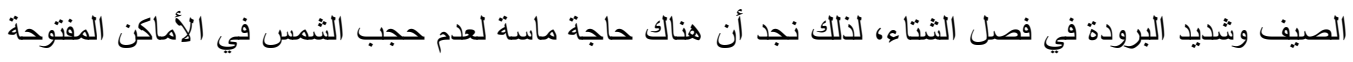

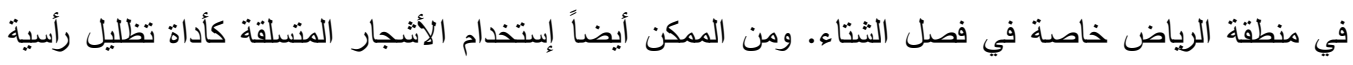

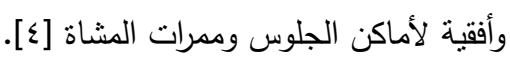

مما لا شك فيه أنه يوصى بإنباع الحلول التصميمية في تصميم المتنزهات والمساحات المفتوحة. ومن تلك

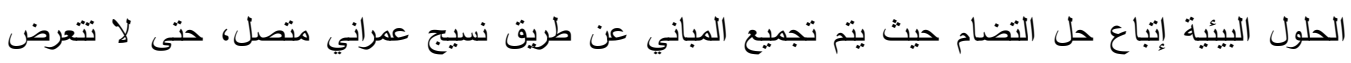

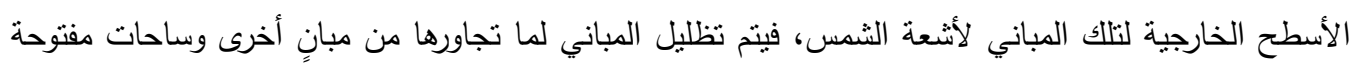

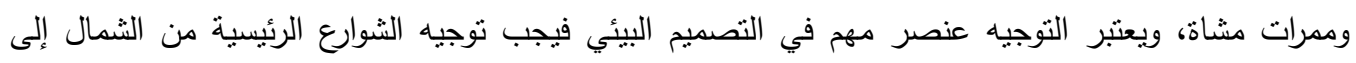


الجنوب حتى تكون عمودية مع حركة الثمس والذي يجعلها تكتسب ظلاً طوال النهار بالإضافة إلى إمكانية

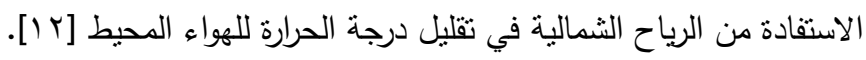
كما أظهرت دراسة لمقارنة درجات حرارة هواء في خمسة مواقع وهى ممر مظلل، وميدان مبلط غبر

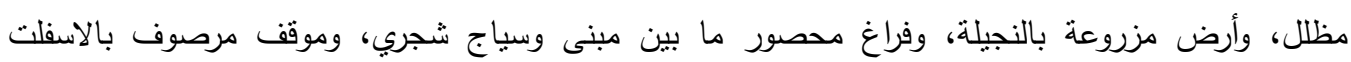

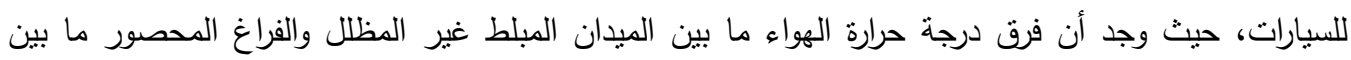

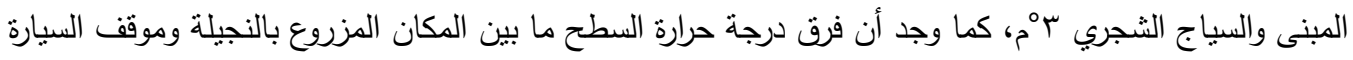

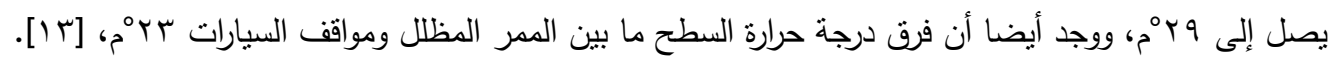
ومن الدراسات التطبيقية لأهية النظليل دراسة قام بها الحمدي وأبانمي برهنت على أن استخدام النباتات في تبريد وتظليل الواجهات الغربية يؤثر إيجابيا على الأداء الحراري للفراغات الداخلي وبالتالي ينعكس على درجة

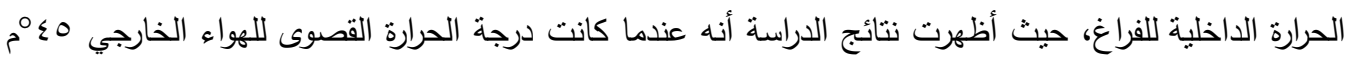

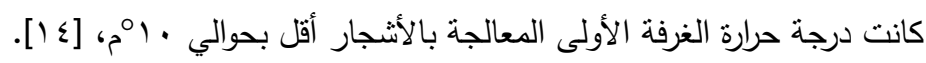

ومن خلال قراءة لدراسة تطبيقية قام بها الحمدي، والعباسي اتضح تأثير مواد التشطيبات الطبيعية

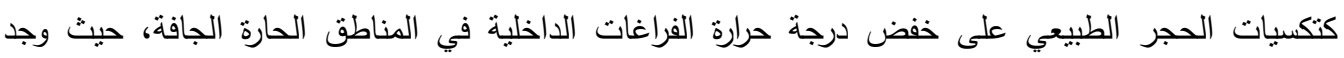

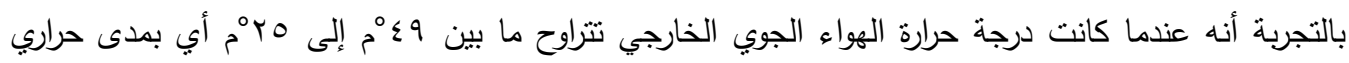

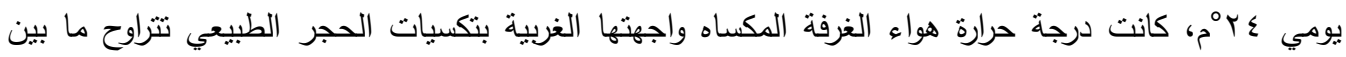

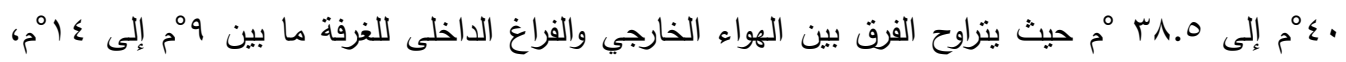

ومن المعروف أن تتسيق النباتات من أثجار وشجيرات وغطاء أرضي في الأماكن المفتوحة والمنتزهات

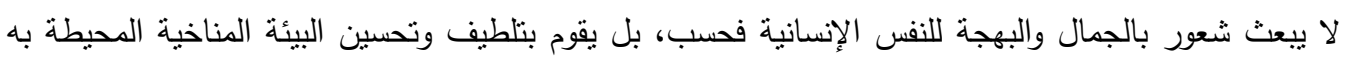

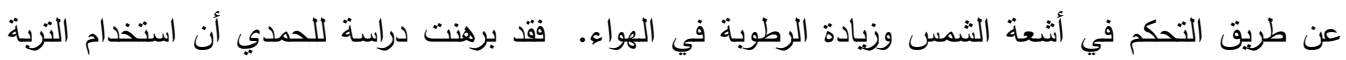

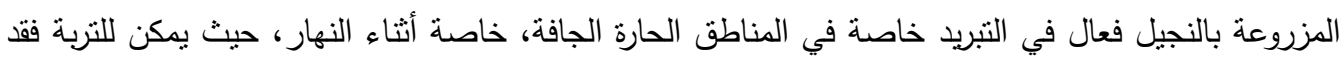
حرارتها المكتسبة من أنعة الثمس بواسطة التبخير من رطوبة التنربة [1 [1].

ويجدر التتبيه هنا على أهمية إستخدام أسلوب ونظام ري فعال وإقتصادي لري تلك الأثجار المستخدمة

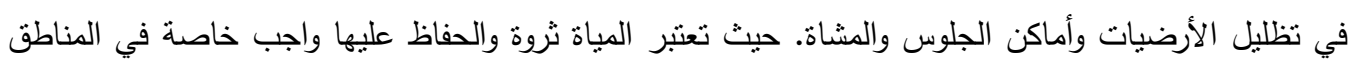

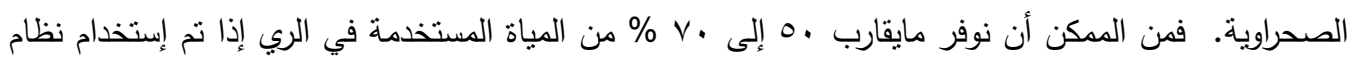

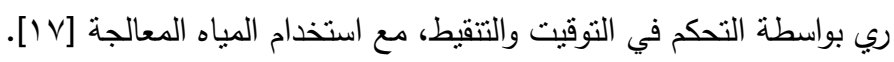

تعنبر الحماية من أشعة الثمس في فصل الصيف من الأمور الهامة خصوصا في المناطق الحارة،

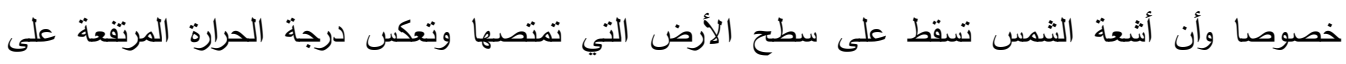

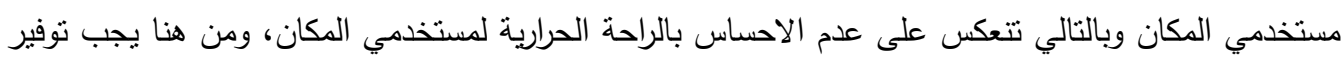


الظل بالموقع وذلك عن طريق استخدام الأثجار كما يجب أيضاً وضع الأشجار بشكل لا يعيق حركة الهواء لأن

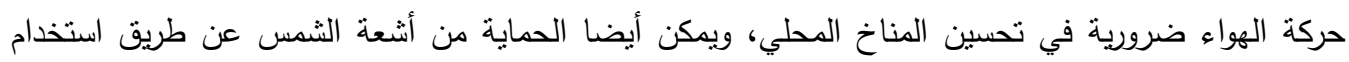
الوسائل الصناعية من المظلات والخيام، [N [1].

\section{منهجية البحث :}

1 - مراجعة لأدبيات البحوث السابقة التي لها علاقة بموضوع البحث (والتي تم توضيحها سابقاً). r - زيارات إستطلاعية ورفع بصري للموقع.

تهذف هذه الزيارات إلى تكوين قاعدة معلومات وتقويم مادي وإنطباعي عن الوضع الراهن لهذه الفراغات والإطلاع

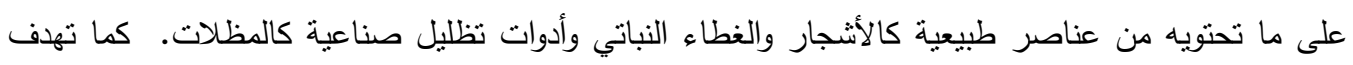

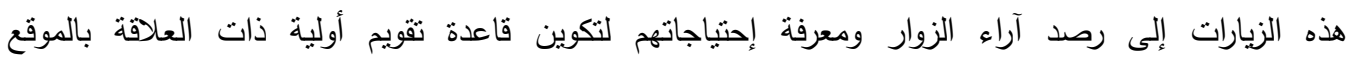

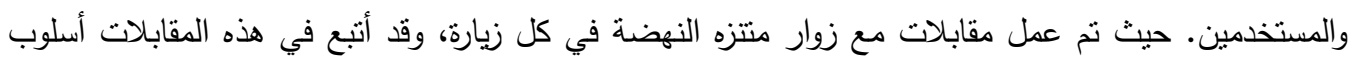

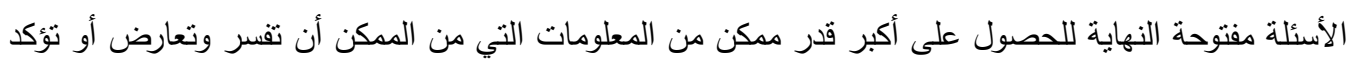
نتائج هذه الدراسة.

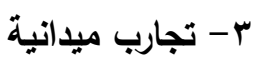

تعتمد هذه التجارب الميدانية على رصد الأداء الحراري لعدد من الفراغات المفتوحة وممرات المشاة الواقعة في

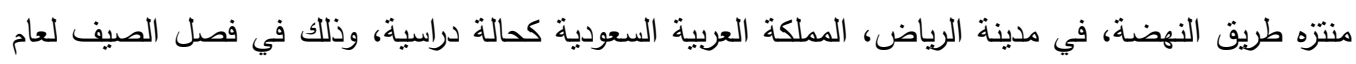

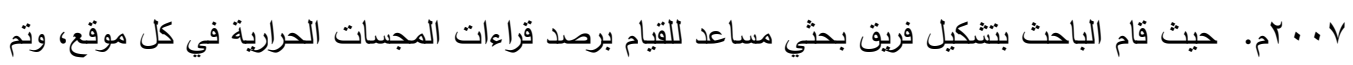

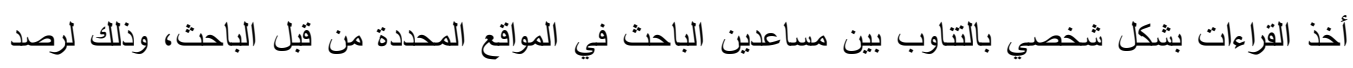

درجة الحرارة والرطوبة النسبية لكل موقع كما هو موضح في الثنكل (1). 


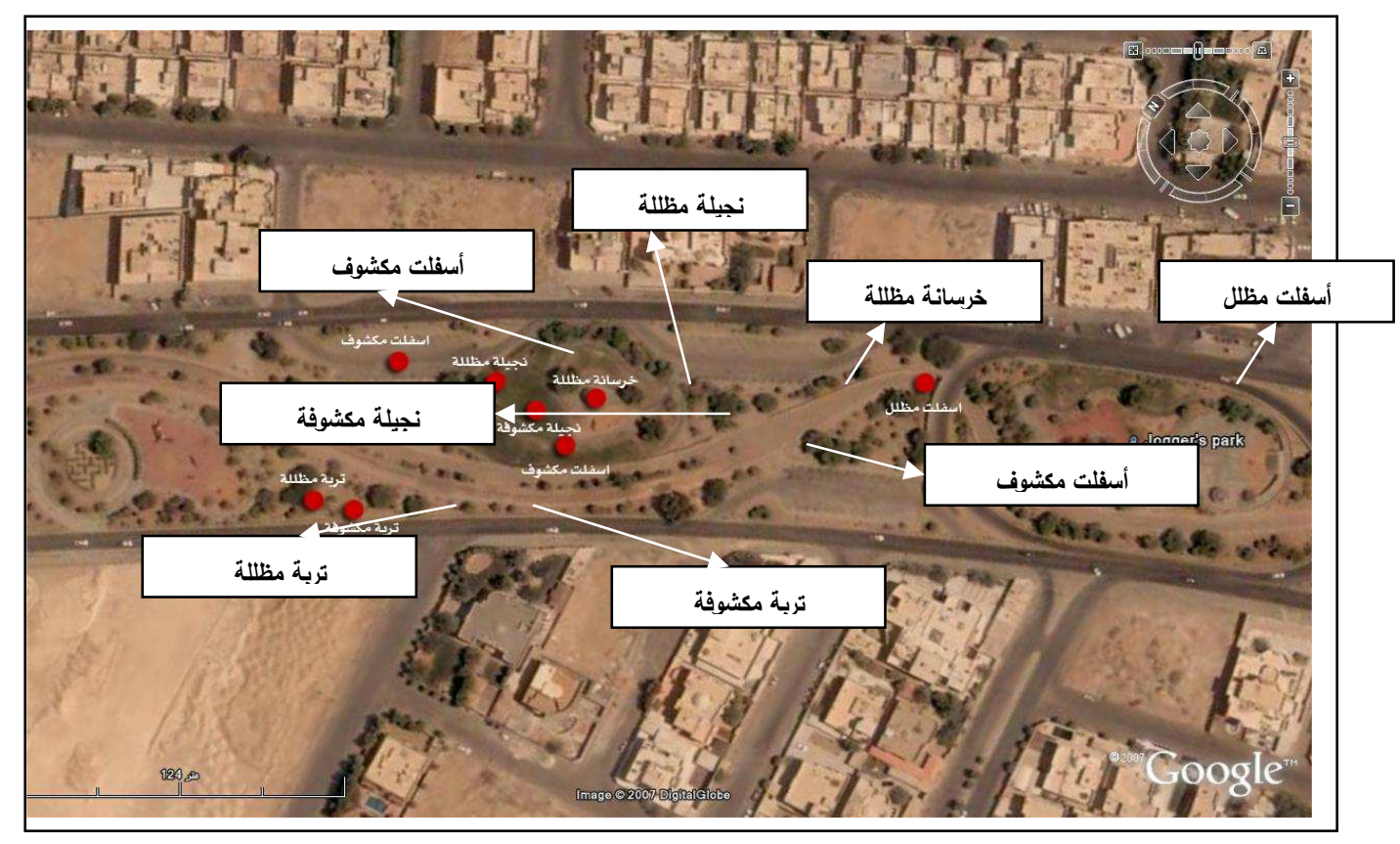

شكل ( ) الفراغات المفتوحة وممرات المشاة الواقعة في متنزه طريق النهظة

وقد أخذت القراءات فوق أنواع مختلفة من الأرضيات (مظللة وغير مظللة) بهدف التوصل إلى قراءات توضح مدى تأثير المواد المستخدمة في الأرضيات على حرارة البيئة المحيطة بالإضافه إلى معرفة مدى ثأثئير التظليل

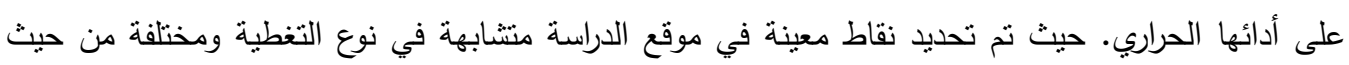

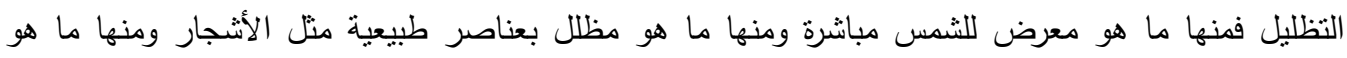
مظلل بعناصر صناعية متل المظلات الخرسانية.

حيث قام الفريق البحثي المساعد بأخذ القراءات على خمس فترات على مدار اليوم الواحد وذلك لصعوبة ترك

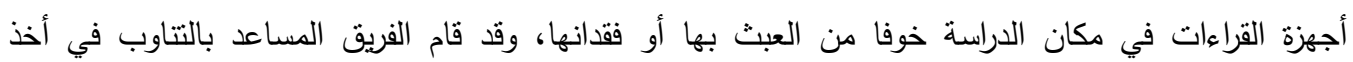

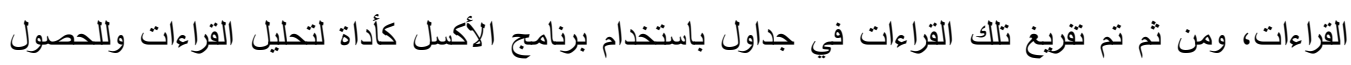
على رسومات بيانية نوضح نتائج التجربة.

\section{تحليل النتائج}

من خلال قراءة وتحليل القراءات المرصودة في جميع المواقع تم التوصل إلى نتائج البحث والتوصيات. وفيما يلي

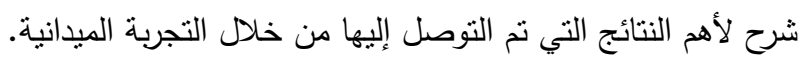


1- الأرضيات الخرسانية (مظلة وغير مظللة)

من خلال تحليل القراءات المرصودة أتضح أن درجة حرارة الهواء فوق أرضية من الخرسانه المكثوفة لأثشعة

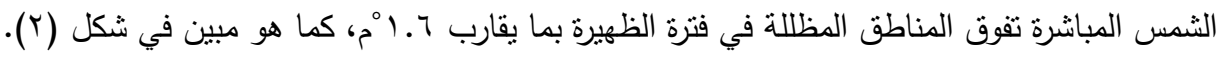

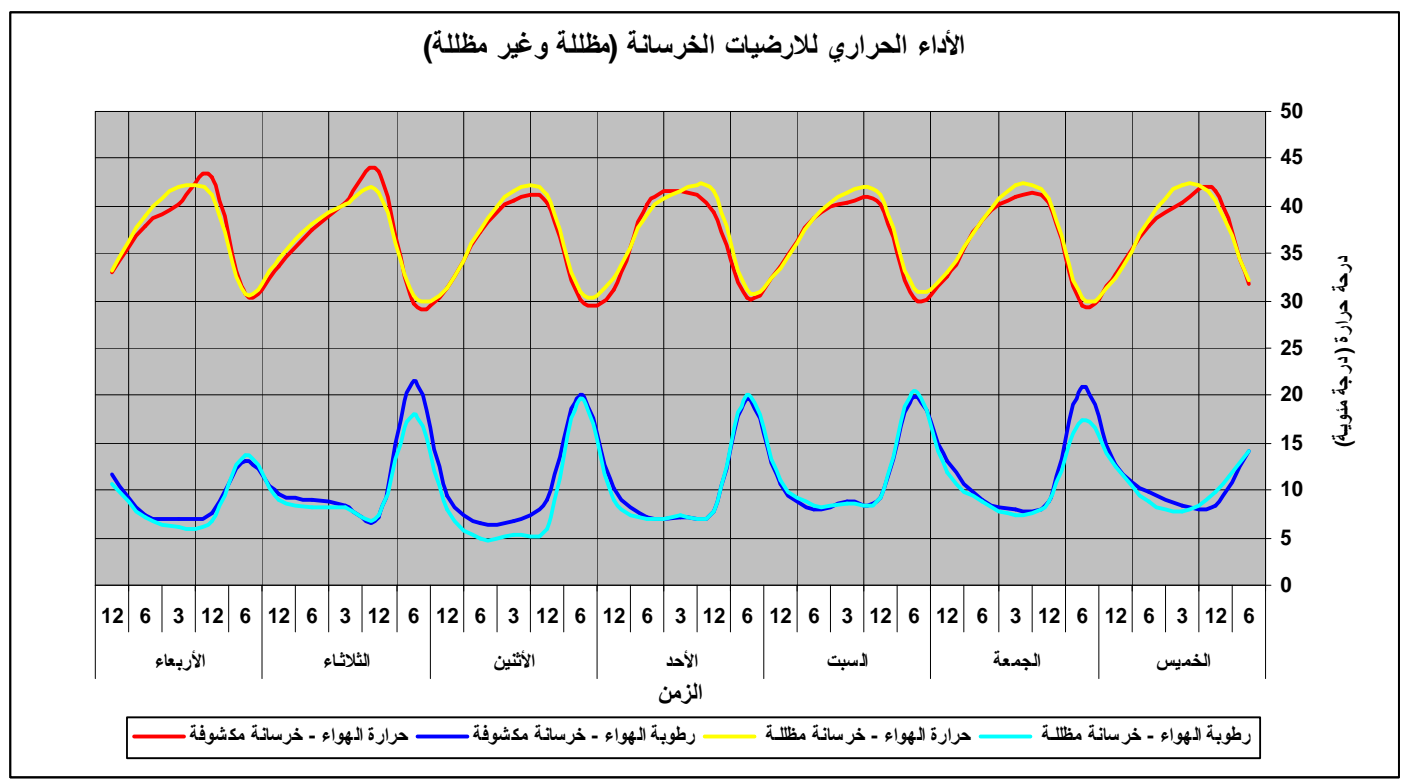

شكل (ץ) الأداء الحراري للمواد الخرسانية المستخدمة في الأرضيات

كما تيين أن مادة الخرسانه غير مناسبة للاستخدام في أدوات النظليل، حيث أن مادة الخرسانه لها خاصية حفظ

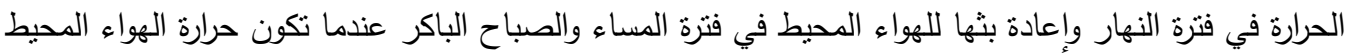

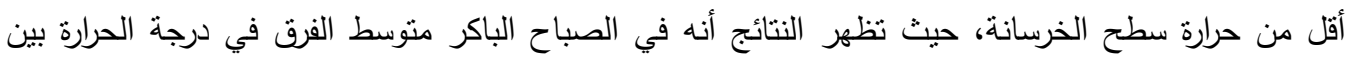

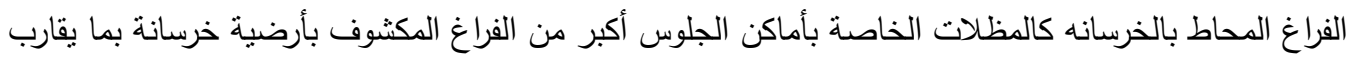

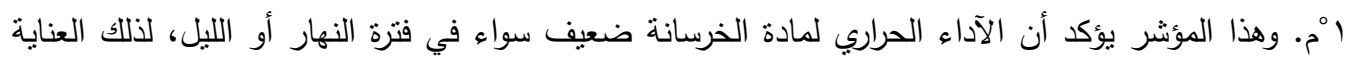

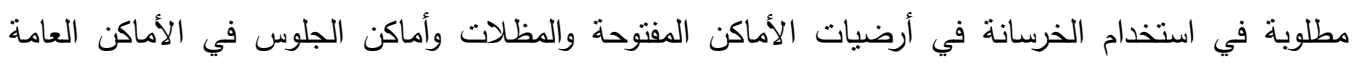

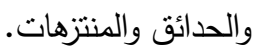

r- النجيلة الخضراء (مظلة وغير مظلة)

لوحظ من القراءات المرصودة أن هناك ما يقارب ع. اْم كفرق بين أعلى درجة حرارة تم رصدها فوق أرضية من

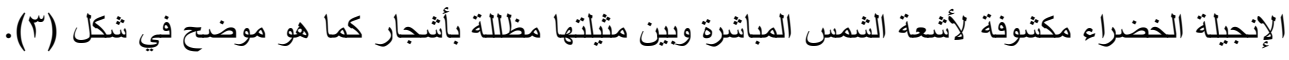




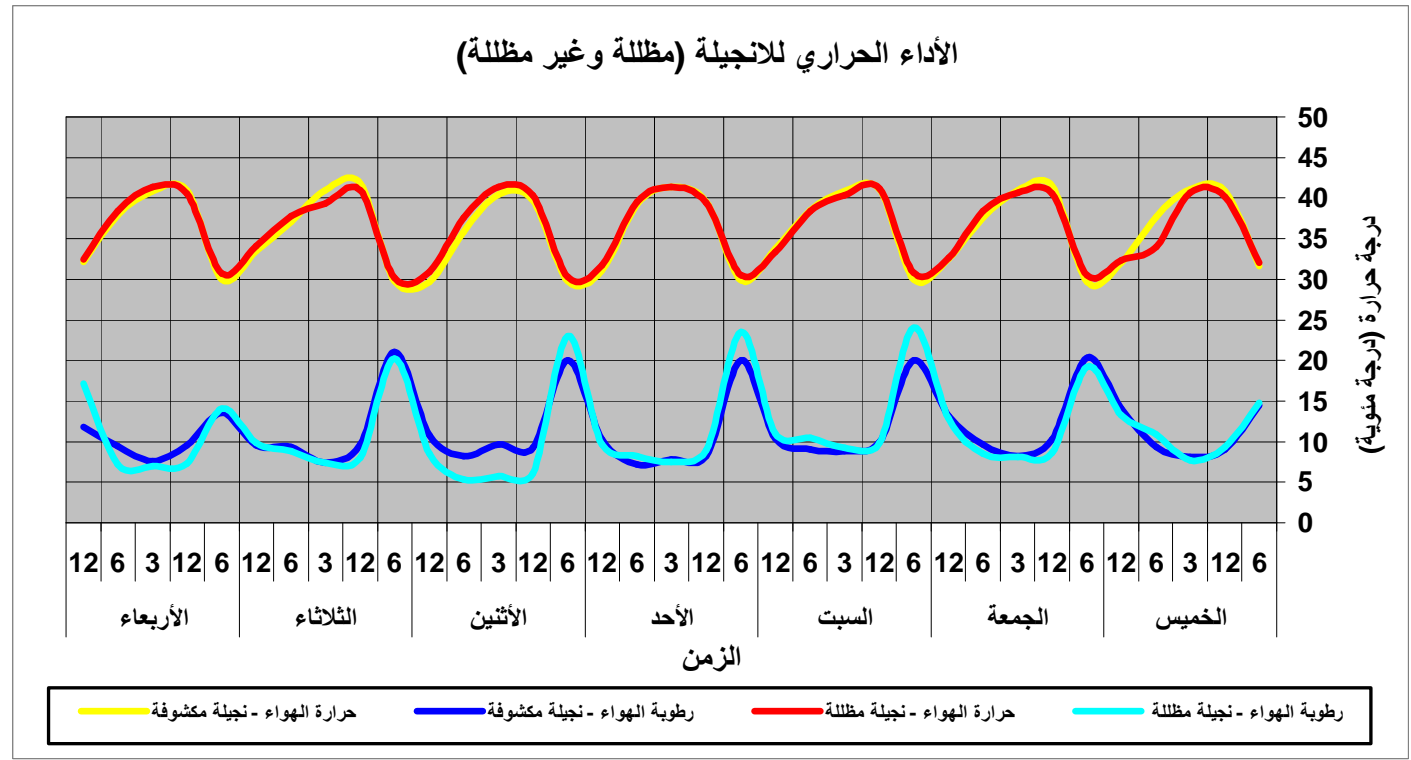

شكل (广) الأداء الحراري للانجيلة داخل المتنزه

وتعمل الاثشار على حماية مناطق الجلوس من أثنعة الثمس المباشرة وأيضا تساهم في زيادة نسبة التبخير الذي الني هو أحد المعايير الهامة في التبريد غير المباشر (Passive Cooling) المستخدم في التصميم البيئي، كما تبين

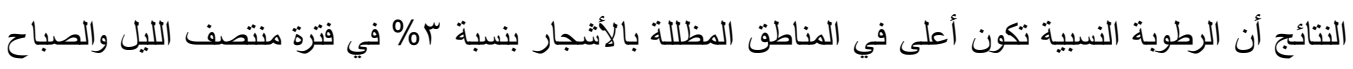

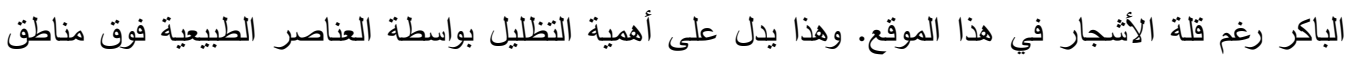
الجلوس على أرضية من الإنجيلة الخضراء. ولكن العناية مطلوبة أيضاً في اختيار نوع ومكان أثنجار النظليل

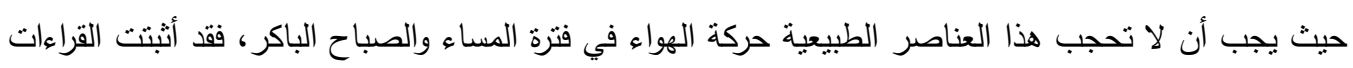

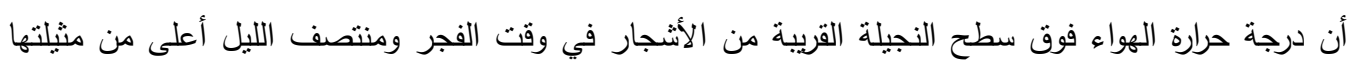

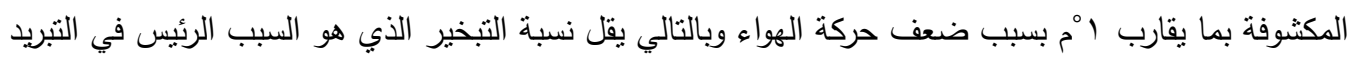

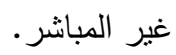

ب- التربة (مظلة وغير مظللة)

يلاحظ من النتائج أن تظليل التربه يمكن أن بساهم في خفض درجة حرارة الهواء المحيط ويمكن أن يحسن الآداء

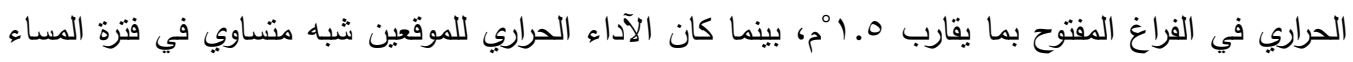
والصباح الباكر ، كما هو موضح في شكل (ع). 


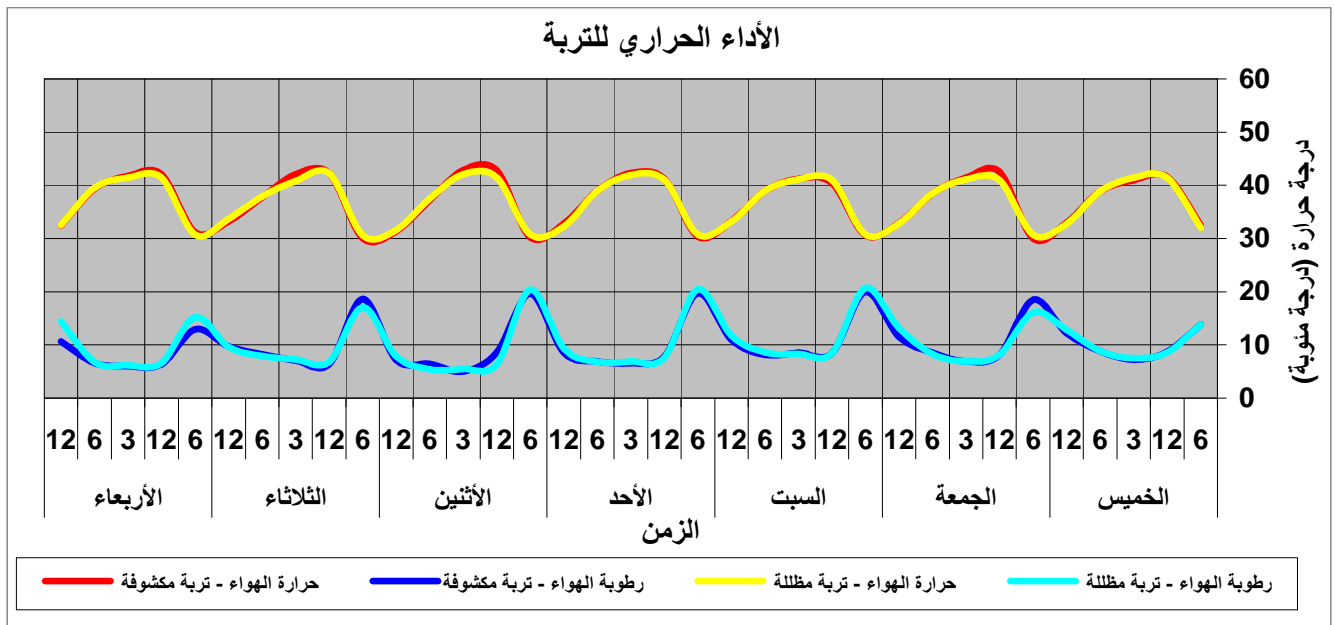

شكل (ع) الأداء الحراري للتربة داخل للمتنزه

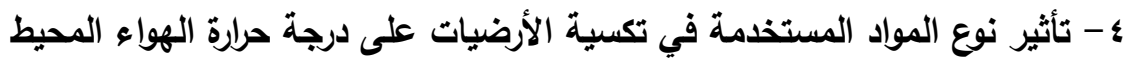

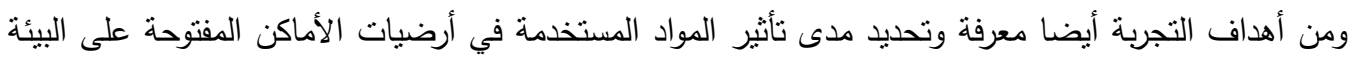
المحيطة من ناحية تأثيرها على درجة الحرارة والرطوبة النسبية. حيث نم رصد درجة الحرارة في مناطق مظللة تم

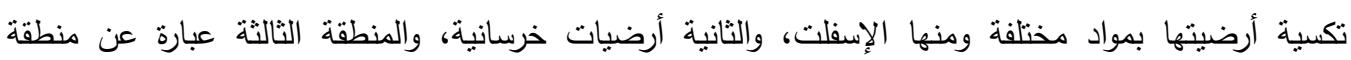

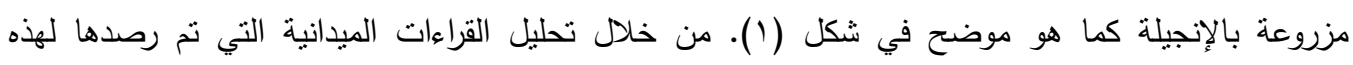

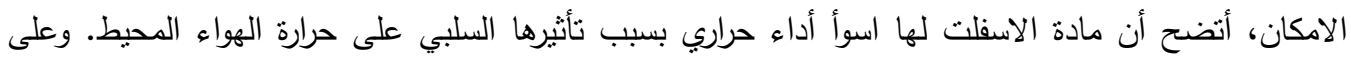

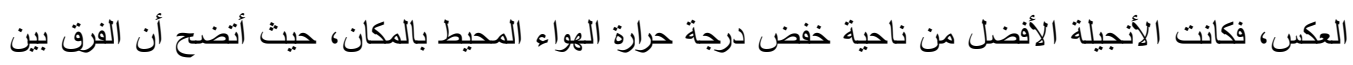

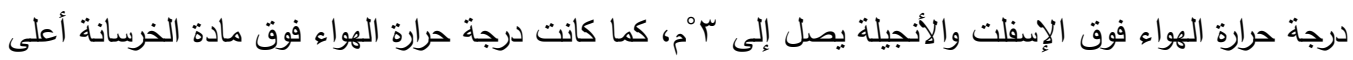

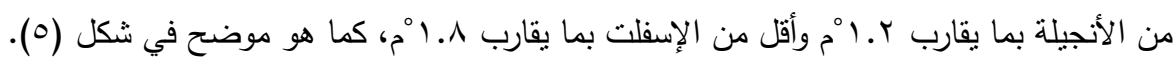

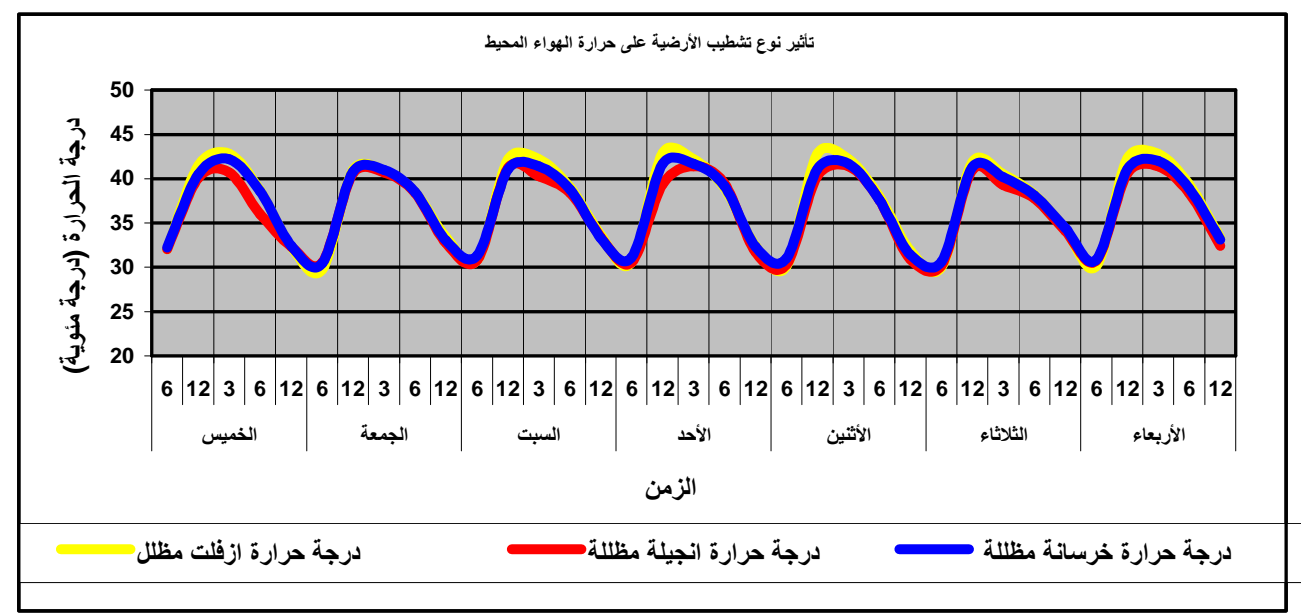

شكل (0) نأثير نوع تتطيب الأرضية على حرارة المكان 
وهذا مؤشر واضح على مناسبة تكثيف استخدام المناطق الخضراء في أماكن الجلوس وممرات المشاه في المناطق

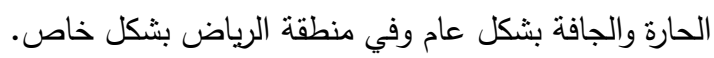

\section{ه- تأثير حركة السيارات على الأداء الحراري للموقع}

ومن أهداف البحث أيضاً تقييم الأداء الحراري لفراغين متتابهين من ناحية نوع أدوات التظليل ونوع مواد تشطيب

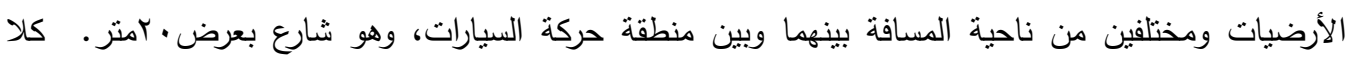

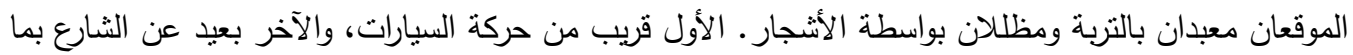
يقارب • امتر، ومن خلال تحليل القراءات أتضح أن درجة حرارة الهواء في الفراغ المفتوح القريب من حركة

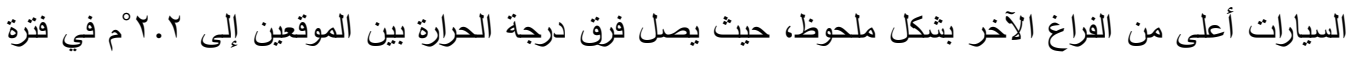

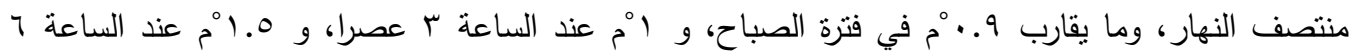
مساءا، وتصل إلى V. ا’م عند منتصف الليل كما هو موضح في شكل (T). وهذا يرجع إلى تأثير مصدر الحرارة الناتج من المركبات وعوادم السيارات والانعكاسات الحرارية المنبعثة من الإسفلت على المناخ المحلي للمنطقة.

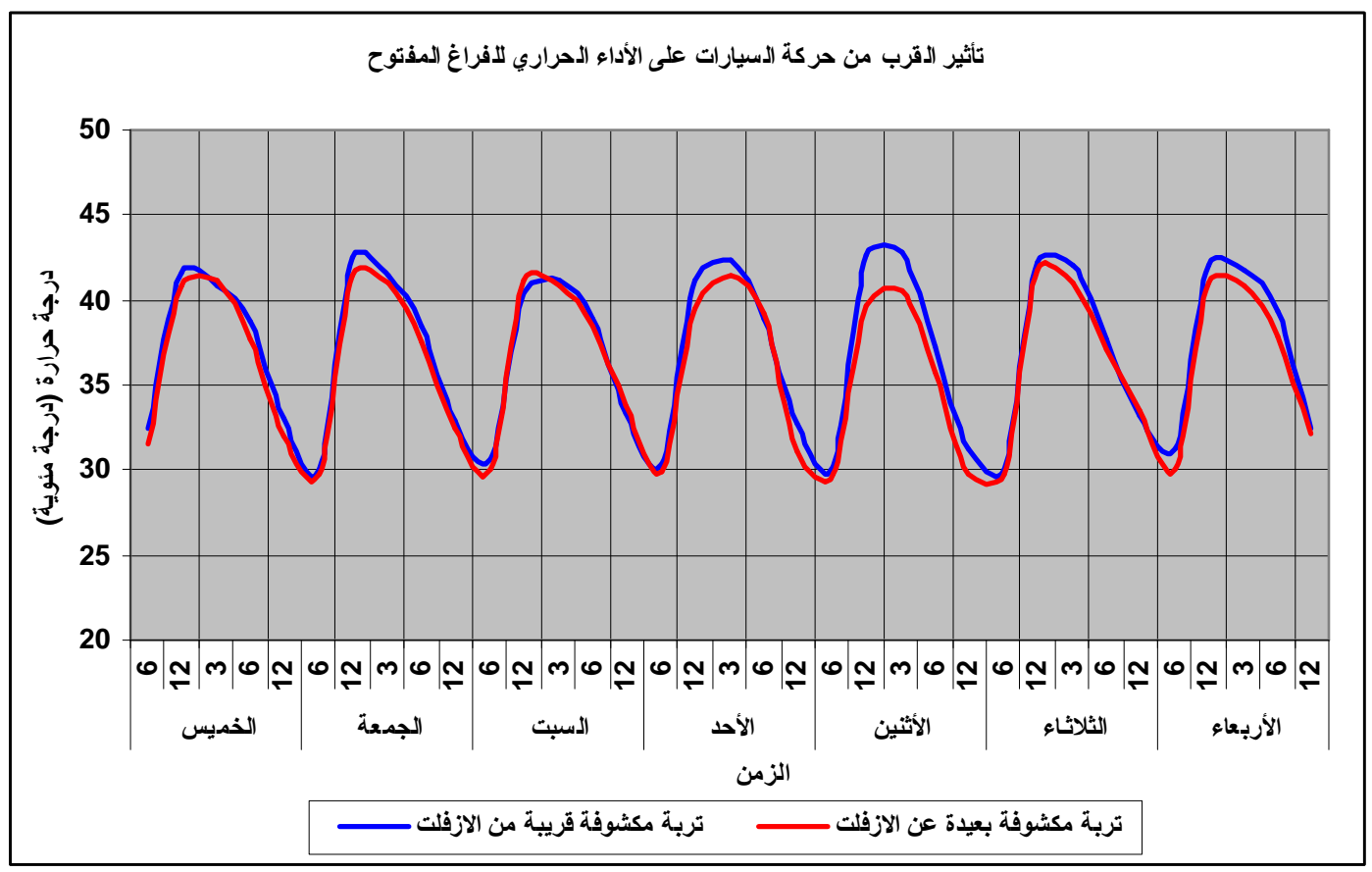

شكل (؟) نأثثر القرب من حركة السيارات على الآداء الحراري للفراغ المفتوح 


\section{النتائج :}

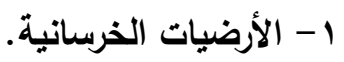

تبين أن مادة الخرسانه غير مناسبة للاستخدام في أدوات التظليل، وذلك يرجع إلى أن مادة الخرسانه لها خاصية

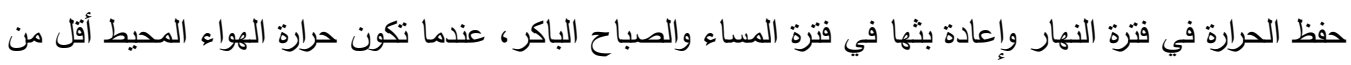

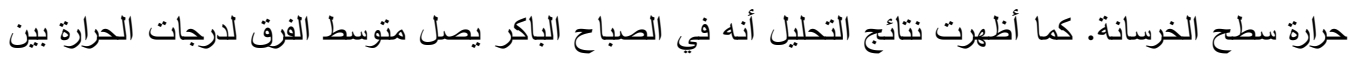

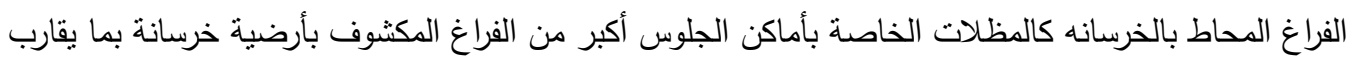

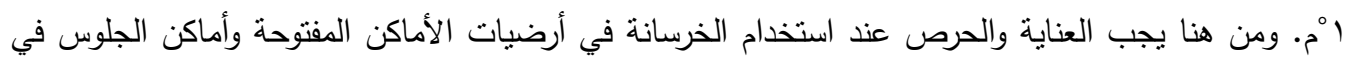
الأماكن العامة والحدائق والمنتزهات.

r- النجيلة الخضراء.

أنضح أن الأشجار والتشجير يعملان على حماية مناطق الجلوس من أنشعة الثمس المباشرة، كما أنها تساهم في

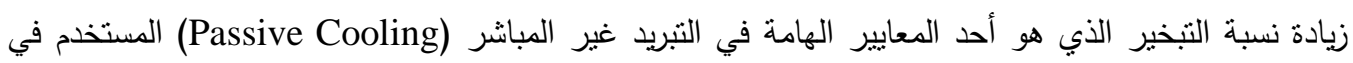

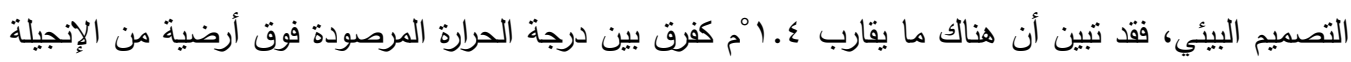

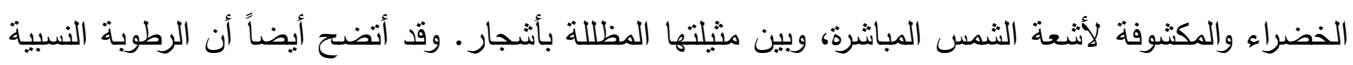

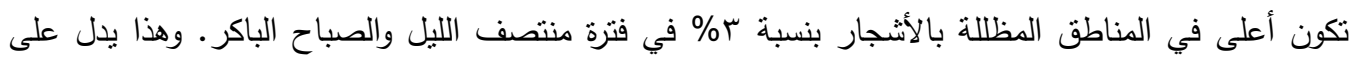

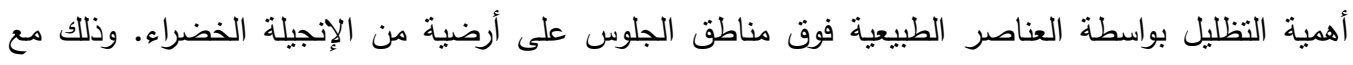

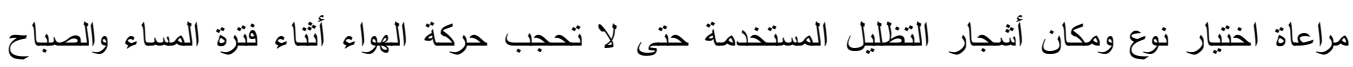

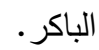

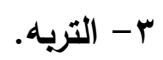

أتضح أن تظليل التربه يساهم في خفض درجة حرارة الهواء المحيط، كما يحسن الآداء الحراري للفراغ المفتوح بما

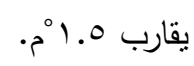

\section{؟ - تأثير نوع المواد المستخدمة في تكسية الأرضيات على درجة حرارة الهواء المحيط.}

- أتضح أن مادة الاسفلت لها اسوأ أداء حراري بسبب تأثنرها السلبي على حرارة الهواء المحيط.

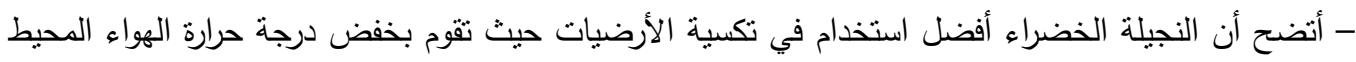

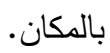

- أنضح أن درجة حرارة الهواء فوق مادة الخرسانة أعلى من النجيلة بما يقارب ؟.اْم وأقل من الإسفلت بما

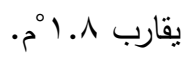

مما سبق يتضح مدى مناسبة تكثيف استخدام المناطق الخضراء في أماكن الجلوس وممرات المشاه في المناطق الحارة والجافة بشكل عام وفي منطقة الرياض بشكل خداص. 


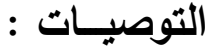

ضرورة تكثيف المناطق الخضراء المظللة في المناطق المفتوحة وممرات المشاة الواقعة في مناخ حار وجاف.

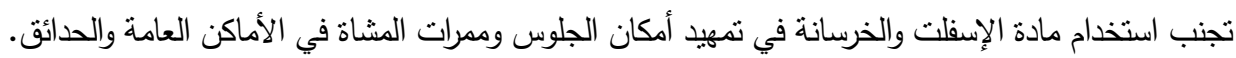

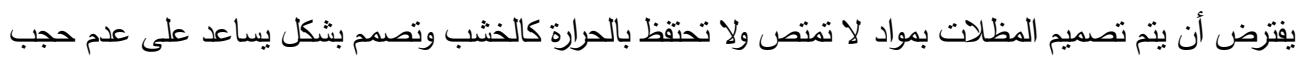
حركة الهواء والتي لها الدور الأساسي في تخفيض درجة حرارة الهواء.

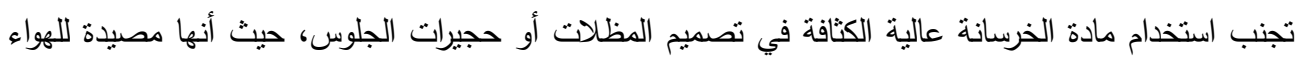

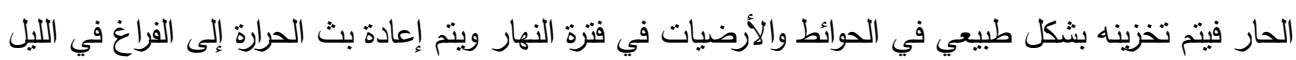
عندما تكون درجة حرارة الهواء أقل من درجة حرارة الاسطح.

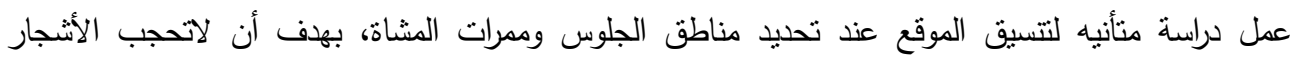

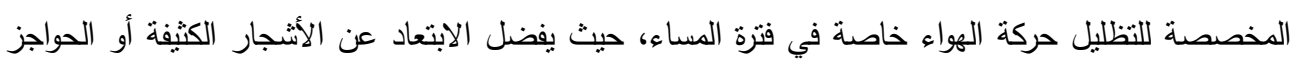

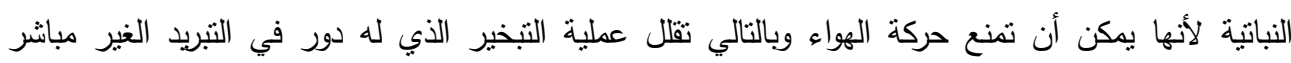
اللفراغ (Passive Cooling). تجنب مادة الإسفلت قدر الإمكان في الأماكن العامة ومناطق الجلوس وممرات المثاة حيث أن لها القدرة في

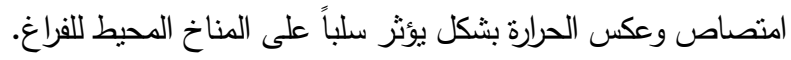

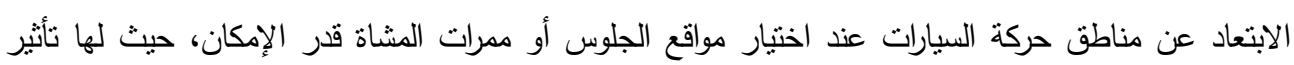
مباثر على زيادة حرارة الهواءو و تقليل الرطوبة النسبية للمناخ المحلي.

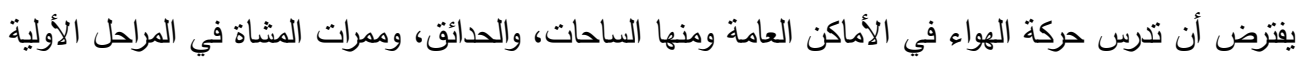

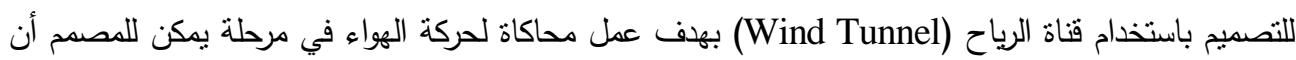
يحسن خلالها تصميم أمكان الجلوس والمناطق الخضراء ونتسيق الموقع داخل المشروع من غير نكاليف إضافية.

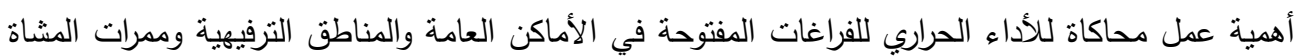

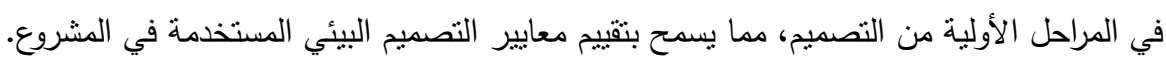

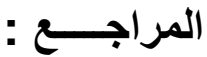

[1] Salmon, Cleveland, 1999. Architectural Design for Tropical Regions, New York: Wiley.

[r] Winter, Steven, 1998. Associates, The passive solar design and construction handbook, in Crosbie, Michael J. (ed.). New York: Wiley.

[ऍ] Chalfoun, Nader, 2000. Computer energy analysis 2, House Energy Doctor Program. University of Arizona. USA.

[๕] Konya, Allan, 1980. Design Primer for Hot Climates, London: Architectural Press.

[॰] Yannas, Simos, 1994. Design of educational buildings-primer. London: Environment and Energy Studies Programme, Architectural Association Graduate School on behalf of the Commission of the European Communities, Directorate General XII for Science, Research and Development, Renewable Energies Unit. 
[1] Cook, Jeffrey, 1980. Landscaping for microclimate advantage in arid zone housing, Housing in Arid Lands Design and Planning, Architectural Press .Ltd. London.

[V] Golany, Gideon, 1980. Housing in arid lands: design and planning, London: Architectural Press.

[ᄉ] Geiger, Rudolf, 1965. The climate near the ground, Cambridge, Mass, Harvard University Press.

[9] Williams, R. J. 1983. Passive Solar Heating, Ann Arbor Science Publishers.

[1.] Simpson, J. R. \& McPherson, E. G., 1998, Simulation of tree shade impacts on residential energy use for space conditioning in Sacramento, http://www.sciencedirect.com/science?_ob=ArticleURL\&_udi=B6VH3-3SX5GRS-

[1 1] Akbari, H., 2001, Shade trees reduce building energy use and $\mathrm{CO}_{2}$ emissions from power plants, http://www.sciencedirect.com/science?_ob=ArticleURL\&_udi=B757C-48CFVCT-

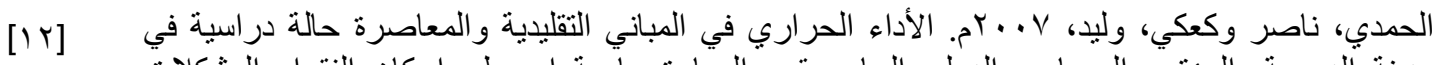

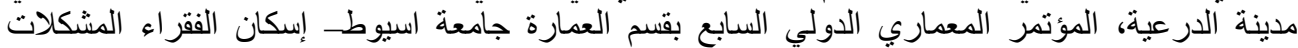
والحلول، جمهورية مصر العربية.

[1T] Givoni, Baruch, 1998. Climate Considerations in Building and Urban Design, Van Nostrand Reinhold.

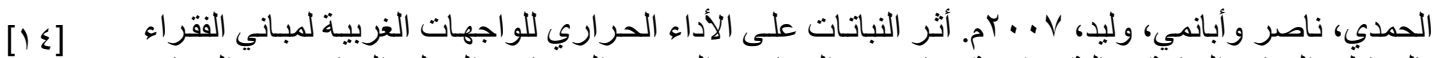

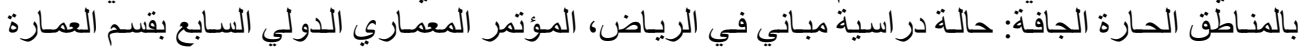

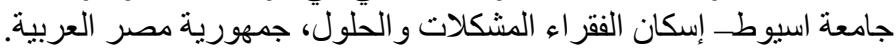

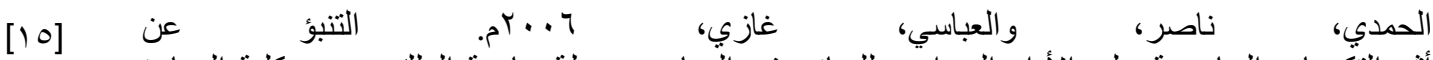
أثر التكسيات الخارجية على الأداء الحراري للمباني في الرياض، مجلة جامعة الملك سعود، كلية العمارة و التخطيط.

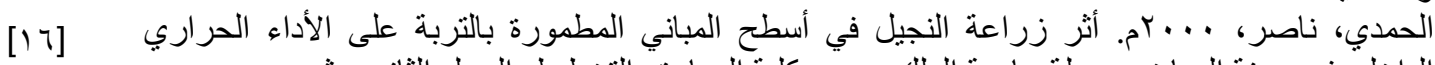
الداخلى في مدينة الرياض، مجلة جامعة الملك سعود، كلية العمارة و التخطيط، المجلد الثاني عشر.

[IV] Green Building Program, 2004. Water efficient irrigation, http://greenbuildings.santa-onica.org/landscape/landscapelab.html.

[1^] Booth, Norman k. \& Hiss, James E., 2002. Residential Landscape Architecture, Design process for the private residence- $-3^{\text {rd }}$ ed. 